\title{
Research Paper \\ Index of Nutritional Quality and Its Association With Serum High Sensitive C-reactive Protein Between Institutionalized and Non-institutionalized Older Adults in Tabriz: A Case-Control Study
}

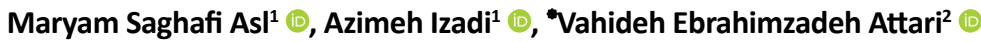

1. Department of Clinical Nutrition, School of Nutrition and Food Sciences, Tabriz University of Medical Sciences, Tabriz, Iran 2. Department of Nutrition and Food Sciences, Maragheh University of Medical Sciences, Maragheh, Iran.

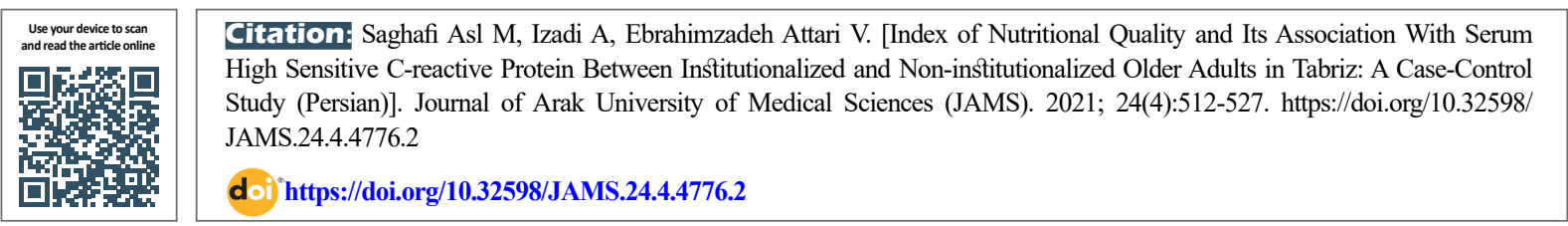

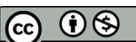

Article Info:

Received: 28 Oct 2020

Accepted: 13 Jul 2021

Available Online: 01 Oct 2021

Keywords:

Aged, Nutrition,

Inflammation, Index

of nutritional quality,

Micronutrient

\section{A B STRACT}

Background and Aim Older adults, particularly those living in nursing homes, are a vulnerable group whose poor nutritional status and inadequate nutrient intake provide the basis for the incidence of diseases and increase their health costs. The aim of the present study was to compare the Index for Nutritional Quality (INQ) between institutionalized (nursing-home) and non-institutionalized (communityliving) older adults and to investigate its association with serum high sensitive C-reactive protein (hs-CRP) level in each group.

Methods \& Materials In this case-control, age- and gender-matched study in Tabriz (East Azarbaijan, Iran), o subjects aged 65 years and older were recruited from nursing homes $(n=76)$ and community $(n=88)$. Anthropometric parameters were measured and body mass index (BMI) was calculated. A three-day record of the foods provided for the nursing home residents were weighed, using a digital scale. The whole food intake of older adults was converted to grams and dietary data were analyzed using Nutritionist IV software. Blood sample was drawn to measure serum hs-CRP level. SPSS software was used for data analysis. Ethical Considerations The present research was approved at Research Ethical Committee of Tabriz University of Medical Sciences (Code: TBZMED.REC.1394.152).

Results In the present study, INQ for all nutrients (except for vitamins A, D, E, biotin, vitamin B6, folic acid, and iron) was significantly different between the two groups $(P<0.05)$. The INQ $<1$ for these nutrients (except for iron) in both groups indicates insufficient intake of these micronutrients. However, INQ for nearly all nutrients (other than selenium) was higher in the community-living older adults, compared to nursinghome residents $(P<0.05)$. The intake of minerals including calcium, magnesium, manganese, selenium, zinc, chromium, sodium, and potassium was also insufficient in both groups. Nursing-home residents did not meet their estimated needs for vitamins B2, B12, and copper. A significant reverse association was observed for serum hs-CRP level and INQ for vitamin $D(P=0.04)$ and calcium $(P=0.038)$ in the communityliving older adults after adjusting for BMI. Such a correlation was also reported between INQ for vitamin $B 12$ and serum hs-CRP level in both groups $(\mathrm{P}=0.02)$.

Conclusion Based on the findings of this study, it is recommended to pay more attention to the nutritional status of older adults, especially those living in nursing-homes. A diet rich in micronutrients, especially vitamin D, calcium, and vitamin B12 may help prevent the development of inflammation in old population.

\section{* Corresponding Author:}

Vahideh Ebrahimzadeh Attari, PhD.

Address: Department of Nutrition and Food Sciences, Maragheh University of Medical Sciences, Maragheh, Iran.

Tel: +98 (41) 37276363

E-mail: ebrahimzadeh.va@gmail.com 


\section{Extended Abstract}

\section{Introduction}

urrently, improving lifestyles, promoting health, and advancing medical knowledge have increased the life expectancy of the elderly in communities [1]. Older adults, particularly those living in nursing homes, are a vulnerable group whose poor nutritional status and inadequate nutrient intake provide the basis for the incidence of diseases and increase their health costs $[4,5]$. There are different dietary indicators to assess the quality of diets. One of the most critical and new indicators of dietary health is the Index of Nutritional Quality (INQ). The INQ for each nutrient is calculated as the ratio of its daily consumption per $1000 \mathrm{kcal}$ to its Recommended Dietary Allowances (RDA) per $1000 \mathrm{kcal}$ [6].

The association of INQ with some chronic diseases such as multiple sclerosis syndrome, breast cancer, ulcerative colitis, and fatty liver has been investigated [14-17]; however, its association with the inflammatory status in older adults is unclear. Therefore, the present study aimed to compare the Index for Nutritional Quality (INQ) between institutionalized (nursing-home) and non-institutionalized (community-living) older adults. We also aimed to investigate its association with serum high sensitive Creactive protein (hs-CRP) level per group.

\section{Materials \& Methods}

In this case-control, age- and gender-matched study in Tabriz City, Iran, the eligible old people aged 65 years and older were recruited from nursing homes and communities. The exclusion criteria were smoking, alcohol consumption, severe physical or mental illness, liver and kidney disease, chronic inflammatory disease, cold or acute infection during the last two weeks. An informed written consent form was obtained from the eligible participants, and a trained questioner completed the other relevant questionnaires.

Anthropometric parameters (height \& weight) were measured using the calibrated equipment, and Body Mass Index (BMI) was calculated. A three-day record of the nursing home residents' foods was weighed using a digital scale. The whole food intake of older adults was converted to grams, and dietary data were analyzed using Nutritionist IV. The INQ for each nutrient was calculated according to the formula mentioned above. Individuals with an average daily energy intake below $800 \mathrm{kcal}$ or more than $4200 \mathrm{kcal}$ were excluded from the study.
A fasting blood sample was drawn to measure serum hsCRP level using the ELISA method. SPSS was used for data analysis. The significance level was set at $\mathrm{P}<0.05$.

\section{Results}

In the present study, eligible older adults from the residents of nursing homes $(\mathrm{n}=76)$ and the community-living older adults $(\mathrm{n}=88)$ were recruited. The Mean $\pm \mathrm{SD}$ age of the residents of the nursing homes was $74.7 \pm 7.9$ years. Moreover, the Mean \pm SD age of the community-living older adults was $72.6 \pm 7.7$ years. As per Table 1, INQ for all nutrients (except for vitamins A, D, E, biotin, vitamin B6, folic acid, and iron) was significantly different between the two groups $(\mathrm{P}<0.05)$. The INQ $<1$ for these nutrients (except for iron) in both study groups indicated insufficient intake of these micronutrients. However, INQ for nearly all nutrients (other than selenium) was higher in the community-living older adults compared to nursinghome residents $(\mathrm{P}<0.05)$. The intake of minerals, including calcium, magnesium, manganese, selenium, zinc, chromium, sodium, and potassium, was insufficient in both groups. Nursing-home residents did not meet their estimated vitamins B2, B12, and copper needs.

The median and Interquartile Range (IQR) for serum hs-CRP in the residents of the nursing homes were 7.29 (2.03 and 20.62$) \mathrm{mg} / \mathrm{L}$, and in the community-living older adults were $5.24(2.46 \& 11.69) \mathrm{mg} / \mathrm{L}$. There was no statistically significant difference between the two groups $(\mathrm{P}=0.145)$. A significant reverse association was observed for serum hs-CRP level and INQ for vitamin D $(\mathrm{P}=0.04)$ and calcium $(\mathrm{P}=0.038)$ in the community-living older adults after adjusting for BMI (Table 2). A correlation was also reported between INQ for vitamin B12 and serum hs-CRP level in both research groups $(\mathrm{P}=0.02)$.

\section{Discussion \& Conclusion}

To the best of our knowledge, this is the first study in which the adequacy of nutrient intake in older adults was assessed through INQ. According to our findings, old people, especially those living in nursing homes, do not receive the recommended nutrients. According to the INQ, there was a significant difference between community-living older adults and the elderly living in nursing homes. These results are consistent with some previous studies. For example, a study conducted on 200 elderly living in the nursing home in Markazi Province [20] reported that $19.6 \%$ of participants had malnutrition, $53.3 \%$ were at risk of malnutrition, and only $27.1 \%$ had good nutrition. Similarly, Saghafi and Vaghef [7] revealed that $53.3 \%$ of elderly people in Tabriz were at risk of malnutri- 
Table 1. Comparison of INQ for each nutrient in the community-living older adults and residents of nursing homes

\begin{tabular}{|c|c|c|c|}
\hline Nutrients* & $\begin{array}{l}\text { Community-living Older Adults } \\
\qquad(\mathrm{n}=\mathbf{8 8 )}\end{array}$ & $\begin{array}{l}\text { Residents of Nursing Homes } \\
\text { ( } n=76)\end{array}$ & $\mathrm{P}^{* *}$ \\
\hline Vitamin A & $0.83(0.52-1.06)$ & $0.87(0.54-2.23)$ & 0.141 \\
\hline Vitamin D & $0.002(0.000-0.005)$ & $0.002(0.001-0.003)$ & 0.416 \\
\hline Vitamin E & $0.17(0.12-0.22)$ & $0.20(0.09-0.28)$ & 0.384 \\
\hline Vitamin B1 & $1.85(1.68-2.04)$ & $1.56(1.42-1.82)$ & $<0.0001$ \\
\hline Vitamin B2 & $1.32(1.02-1.69)$ & $0.95(0.85-1.23)$ & $<0.0001$ \\
\hline Vitamin B3 & 1.58 (1.39-1.77) & 1.49 (1.31-1.54) & $<0.0001$ \\
\hline Vitamin B6 & $0.83(0.64-1.01)$ & $0.88(0.58-1.40)$ & 0.520 \\
\hline Vitamin B9 & $0.46(0.36-0.57)$ & $0.48(0.27-0.62)$ & 0.621 \\
\hline Vitamin B12 & $1.39(0.92-1.83)$ & $0.92(0.59-1.21)$ & $<0.0001$ \\
\hline Vitamin C & $0.69(0.44-1.14)$ & $0.37(0.25-0.61)$ & $<0.0001$ \\
\hline Iron & $2.08(1.84-2.78)$ & $2.32(1.53-2.87)$ & 0.900 \\
\hline Calcium & $0.69(0.59-0.97)$ & $0.63(0.4-0.71)$ & $<0.0001$ \\
\hline Magnesium & $0.51(0.41-0.60)$ & $0.44(0.31-0.47)$ & $<0.0001$ \\
\hline Manganese & $0.83(0.61-1.23)$ & $0.64(0.44-0.83)$ & $<0.0001$ \\
\hline Selenium & $0.18(0.14-0.25)$ & $0.22(0.16-0.3)$ & 0.012 \\
\hline Zinc & $0.70(0.56-0.87)$ & $0.61(0.51-0.79)$ & $<0.0001$ \\
\hline Copper & $1.14(0.92-1.64)$ & $0.96(0.73-1.23)$ & 0.006 \\
\hline Vitamin B5 & $0.94(0.74-1.15)$ & $0.65(0.52-0.81)$ & $<0.0001$ \\
\hline Biotin & $0.58(0.35-0.73)$ & $0.45(0.44-0.68)$ & 0.966 \\
\hline Chromium & $0.11(0.06-0.22)$ & $0.07(0.04-0.13)$ & 0.009 \\
\hline Sodium & $0.83(0.57-1.12)$ & $0.55(0.49-0.74)$ & $<0.0001$ \\
\hline Potassium & $0.52(0.41-0.63)$ & $0.36(0.29-0.45)$ & $<0.0001$ \\
\hline
\end{tabular}

*Values are presented as median (25th, 75th percentiles); **P indicates the comparison between groups by Mann-Whitney U test.

tion, and $2.7 \%$ were malnourished. According to the results of a review study [5], the prevalence of malnutrition in the Iranian elderly is high (12.2\%). The prevalence of malnutrition was higher in those living in nursing homes than community-living older adults. A study in Turkey also reported that the intake of nutrients in the elderly living in nursing homes was less than the recommended amounts [21].
In the present study, there was a reverse correlation between INQ for dietary calcium intake and serum hs-CRP levels, i.e., consistent with the results of Katsuura-Kamano et al. [25]. Moreover, our results suggested a significant reverse correlation between INQ for dietary vitamin B12 intake and serum hs-CRP after adjustment for BMI. In conclusion, it is recommended to pay more attention to the nutritional status of older adults, especially those living in nursing homes. It seems that a diet rich in mi- 
Table 2. The correlation of nutrient's INQ with serum level of hs-CRP in older adults

\begin{tabular}{|c|c|c|c|c|}
\hline \multirow{2}{*}{ Nutrients* } & \multicolumn{2}{|c|}{ Community-living Older Adults ( $n=88$ ) } & \multicolumn{2}{|c|}{ Residents of Nursing Homes ( $n=76$ ) } \\
\hline & Correlation Coefficient & $\mathbf{p}^{*}$ & Correlation Coefficient & P* \\
\hline Vitamin A & 0.14 & 0.08 & -0.09 & 0.48 \\
\hline Vitamin D & -0.22 & 0.04 & -0.13 & 0.29 \\
\hline Vitamin E & -0.08 & 0.43 & 0.2 & 0.10 \\
\hline Vitamin B1 & -0.01 & 0.86 & 0.18 & 0.14 \\
\hline Vitamin B2 & -0.02 & 0.81 & -0.06 & 0.60 \\
\hline Vitamin B3 & 0.08 & 0.45 & -0.06 & 0.61 \\
\hline Vitamin B6 & 0.04 & 0.66 & -0.01 & 0.91 \\
\hline Vitamin B9 & -0.02 & 0.80 & -0.02 & 0.84 \\
\hline Vitamin B12 & -0.32 & 0.02 & -0.31 & 0.02 \\
\hline Vitamin C & 0.05 & 0.63 & -0.11 & 0.38 \\
\hline Vitamin B5 & -0.07 & 0.50 & -0.04 & 0.72 \\
\hline Biotin & -0.05 & 0.60 & 0.19 & 0.12 \\
\hline Iron & -0.03 & 0.77 & 0.2 & 0.10 \\
\hline Calcium & -0.26 & 0.038 & -0.11 & 0.36 \\
\hline Magnesium & -0.05 & 0.63 & 0.16 & 0.20 \\
\hline Manganese & -0.06 & 0.56 & 0.08 & 0.48 \\
\hline Selenium & -0.03 & 0.70 & 0.08 & 0.48 \\
\hline Zinc & -0.15 & 0.15 & 0.06 & 0.61 \\
\hline Copper & 0.11 & 0.27 & -0.04 & 0.74 \\
\hline Chromium & 0.15 & 0.14 & -0.06 & 0.60 \\
\hline
\end{tabular}

*P indicates Partial Correlation test after adjusting for BMI.

cronutrients, especially vitamin $\mathrm{D}$, calcium, and vitamin B12, may help prevent the development of inflammation in the aged population.

\section{Ethical Considerations}

\section{Compliance with ethical guidelines}

The present research was approved by Tabriz University of Medical Sciences (Code: TBZMED.REC.1394.152). All subjects were informed about the study and signed a written informed consent form.

\section{Funding}

The present study was conducted with the financial support of the Nutrition Sciences Research Center of Tabriz University of Medical Sciences.

\section{Authors' contributions}

All authors met the standard writing criteria based on the recommendations of the International Committee of Medical Journal Publishers (ICMJE) and were equally involved in designing and writing the article as follows: Design and conceptualization: Maryam Saghafi Asl and Vahideh Ebrahimzadeh Attari; Research and sampling 
method: Maryam Saghafi Asl, Vahideh Ebrahimzadeh Attari and Azimeh Izadi; Data analysis and interpretation: Azimeh Izadi; Text Writing and Review: All Authors.

\section{Conflicts of interest}

The authors declared no conflicts of interest.

Acknowledgements

We wish to express our appreciation to the Nutrition Research Center, Tabriz University of Medical Sciences, for the financial support. We also would like to thank all of the old people who participated in the study. 
ارزيابى شاخص كيفيت ثغذيهاى وارتباط آن با سطح سرمى ثروتئين واكثشيذير C با حساسيت

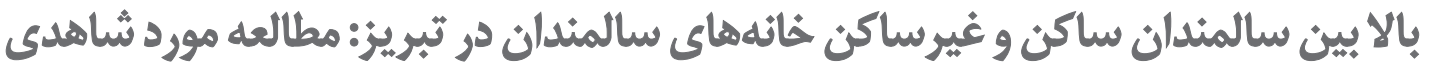

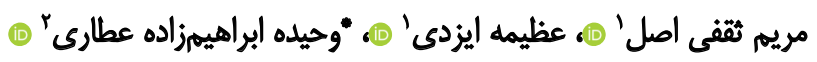

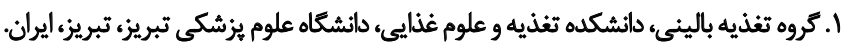

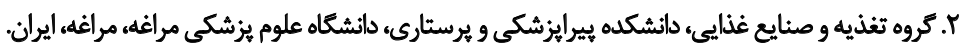

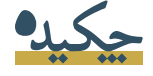

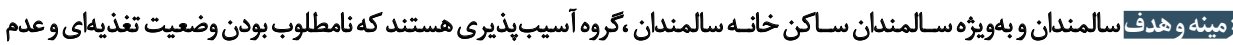

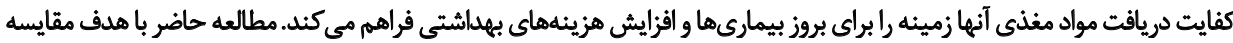

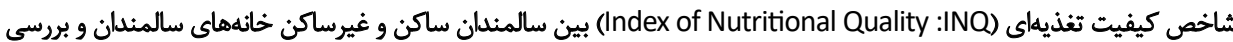

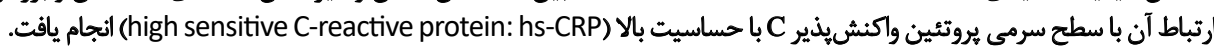

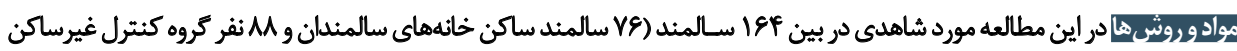

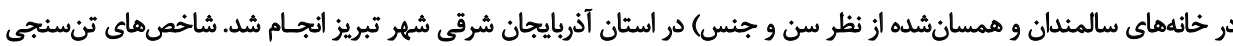

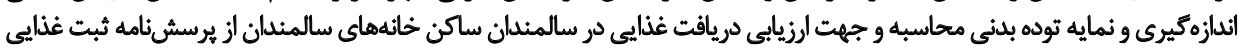

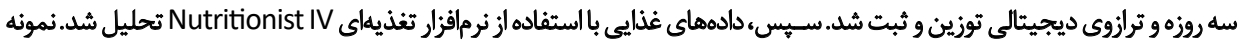

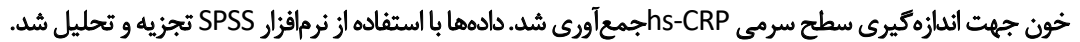

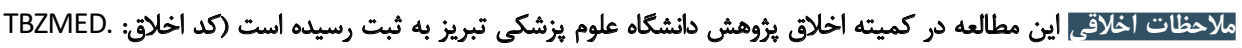
.REC.1394.152

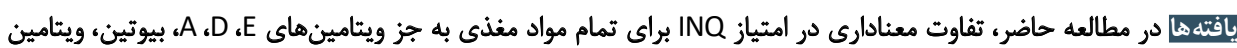

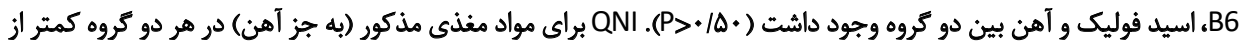

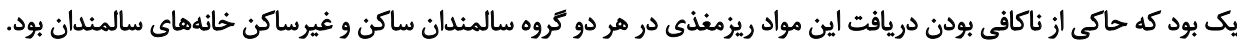

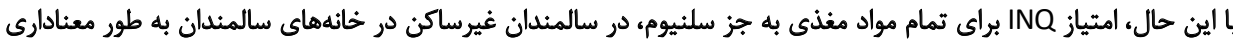

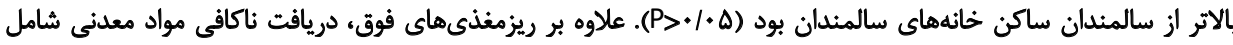

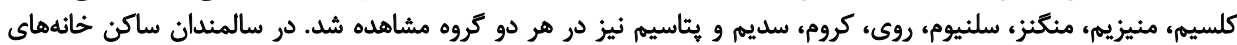

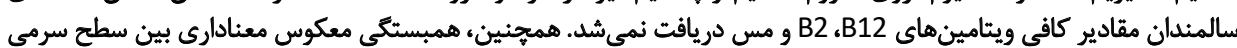

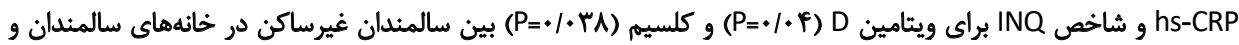

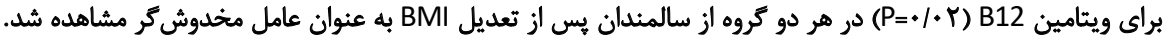

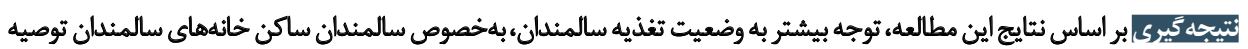

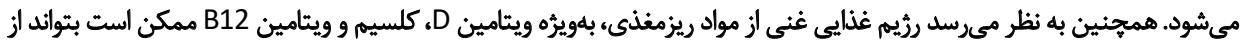
ايجاد الثهاب در اين كروه سنى بيشعَّيرى كند.
اطلاعات مقاله: - - إن

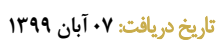

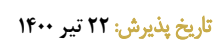

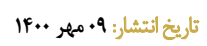

كليدوارهها:

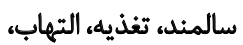
شاخص كيفيت تغذيهائ، مواد ريزمغئى

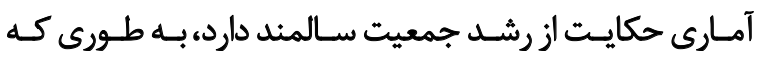

مقدمه

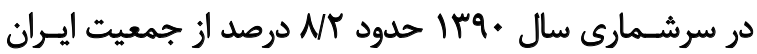

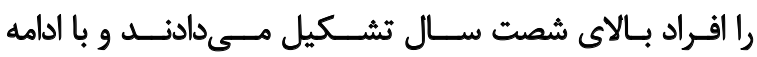

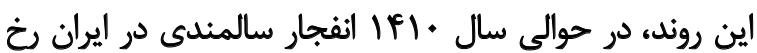

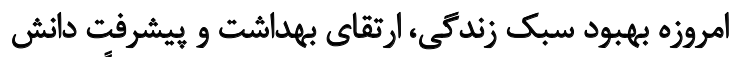

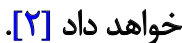

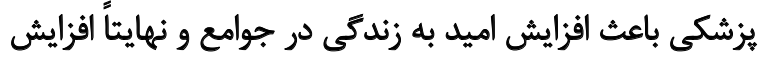

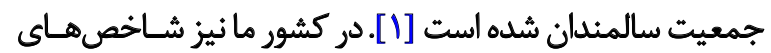




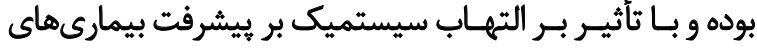

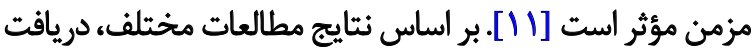

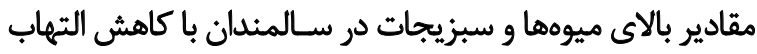

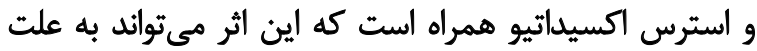

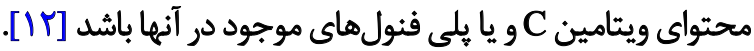

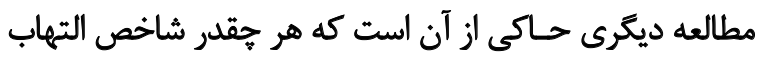
رزيم غذايى در سالمندان بالاتر باشد، خطر شكستكى استخ استخوان

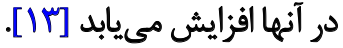
ارتباط شاخص كيفيت تغذيهاى با بعضى از بيمارىهاى مزمن

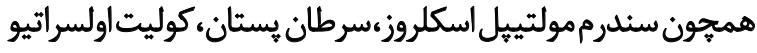

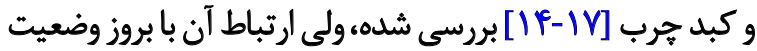

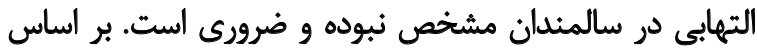

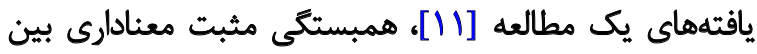

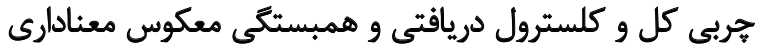

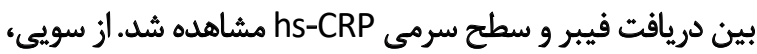

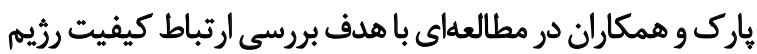

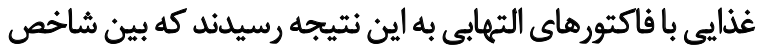

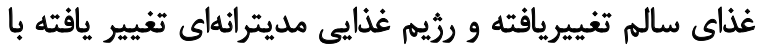

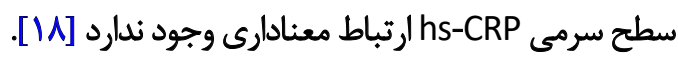
كرد و همكاران [19] نشان دادند كه ارتباط معنادار آمارى

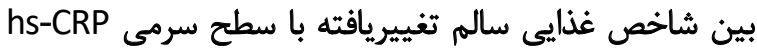

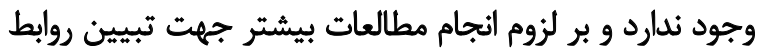

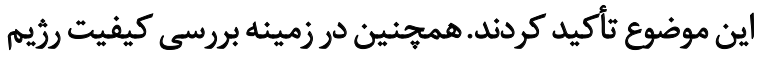

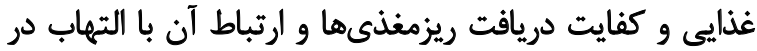
جمعيت سـالمندان مطالعات بسيار اندكى انجـام شده است.

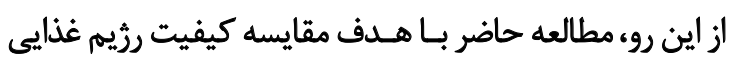
با استفاده از شاخص كيفيت تغذيهاى، بين سالمنداندان ساكن

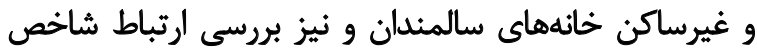

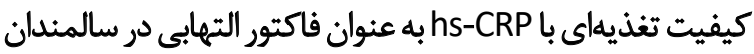
ساكن خانههاي سالمندان و سالمندان جامعه انجام كرفت.

\section{مواد و روش ها}

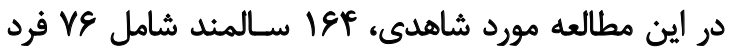

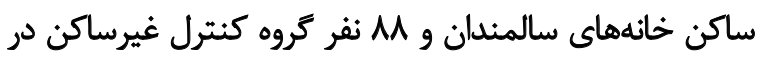

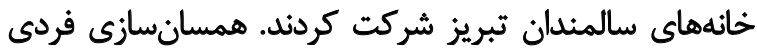

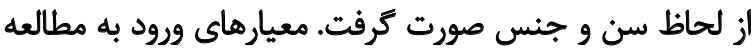

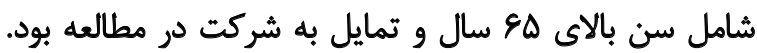

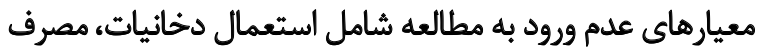

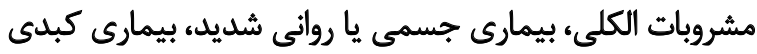

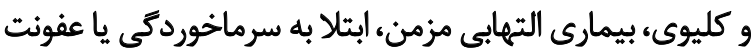

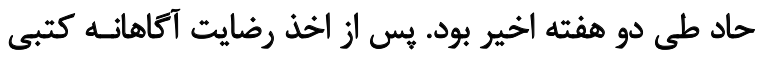

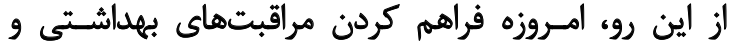

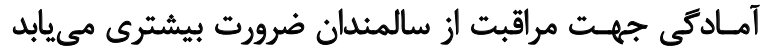

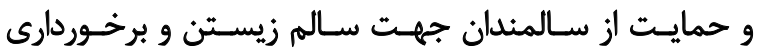

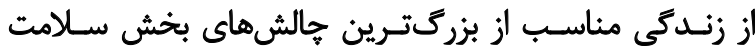

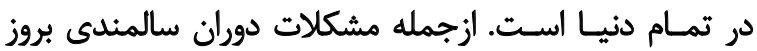

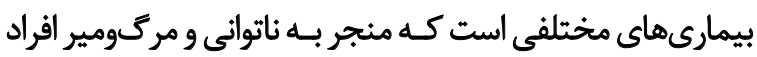

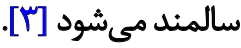

بر اساس مطالعات، وضعيت تغذيهاي، نقش مهمي در سلامت

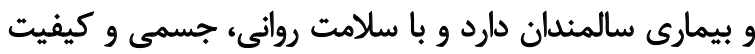

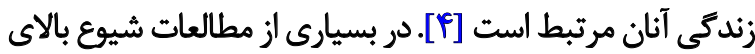

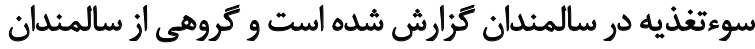

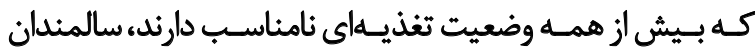

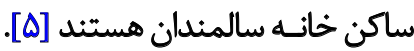

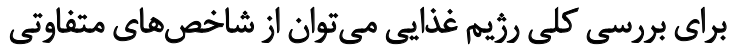

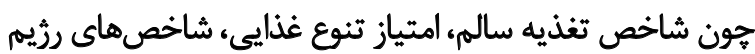

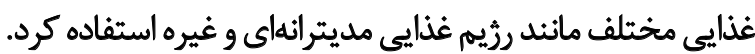

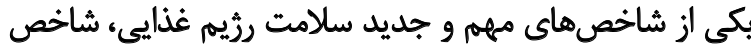

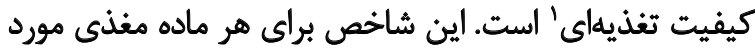

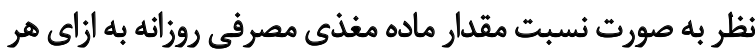

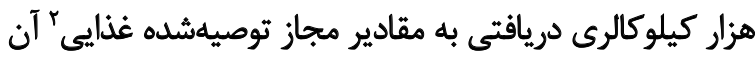

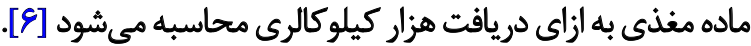
مطالعات اندكى به مقايسه دريافت غذايي سالمندان ساكن

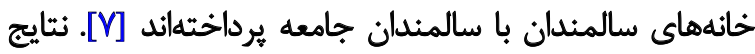

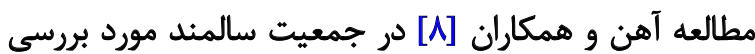

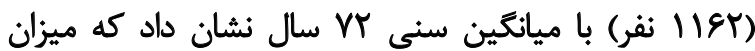

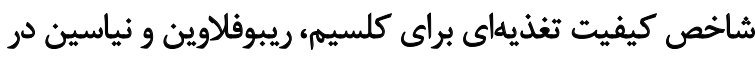

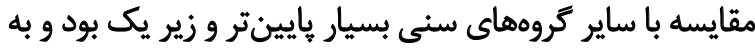

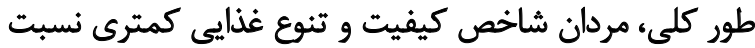

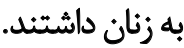

نتايج مطالعه لي و همكاران [9] در بررسى سى فرد سالمند

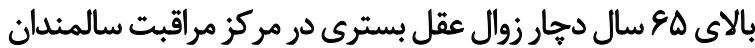

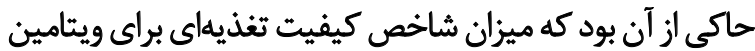

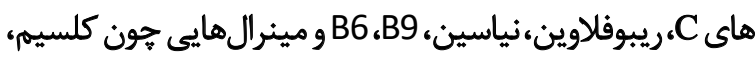

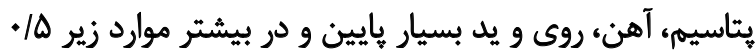

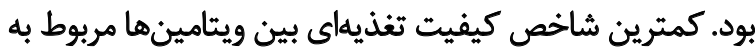

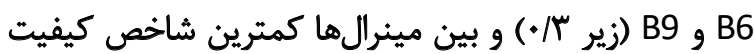

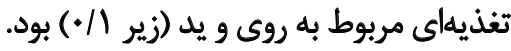

التهاب مزمن نقش مهمي در بروز بسيارى از بيمارىهاى

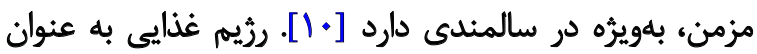

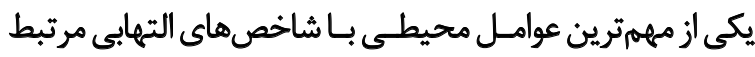

1. Index of Nutritional Quality

2. Recommended Dietary Allowances 
براى بررسى نرمال بودن دادهها ازٔ آزمون كولموكروف اسميرنف

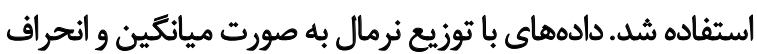

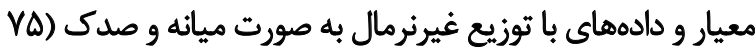

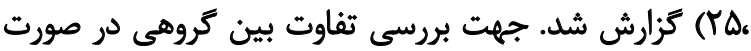

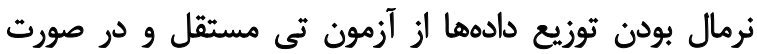

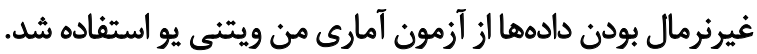

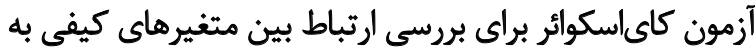

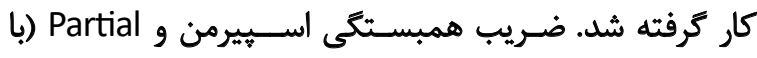

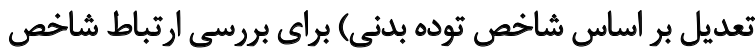

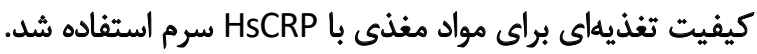

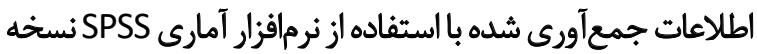

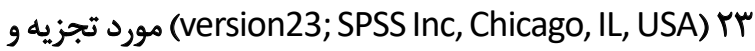
تحليل قرار كرفت و ه \& P معنادار در نظر كرفته شد.

يافتهاها

در اين مطالعه Iff نفر، \& V نفر ساكن خانه سالمندان و

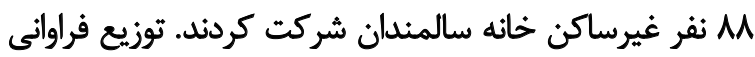

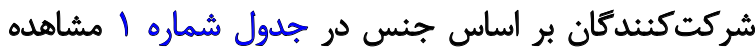

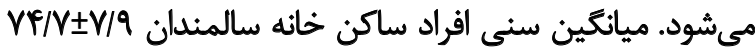

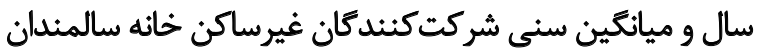

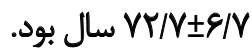

با توجه به توزيع غيرنرمال شاخص كيفيت تغذيهاى، از آزمون

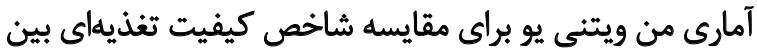

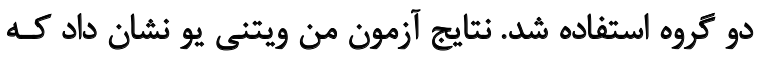

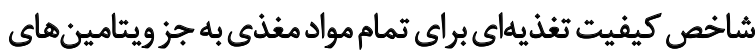

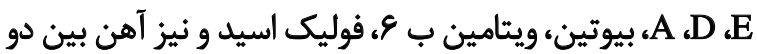

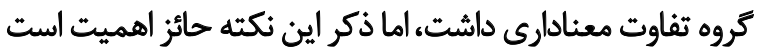

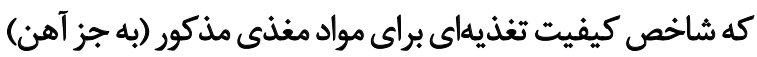

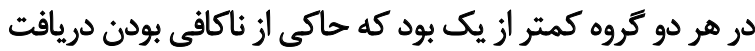

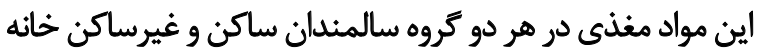

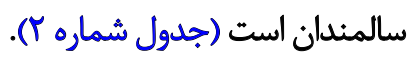

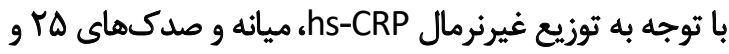

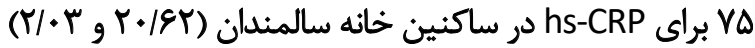

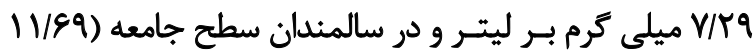

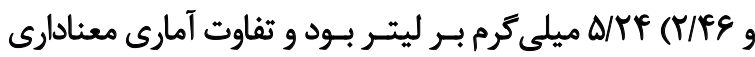

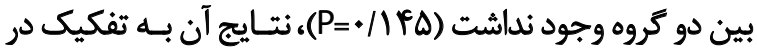

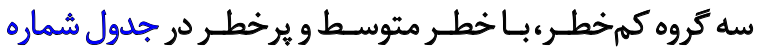

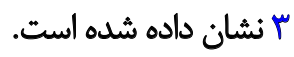

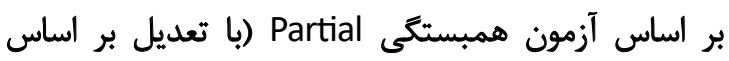

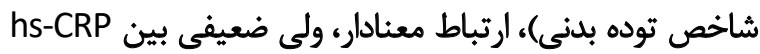

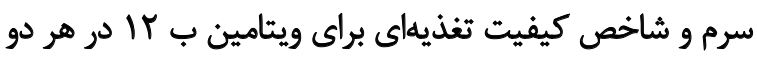

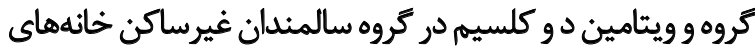
سالمندان مشاهده شد (جدول شماره \&).
جهت شركت در مطالعه، يرسشنامههاي مربوطه توسط يرسشكَر

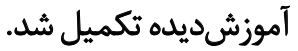

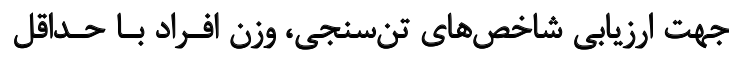

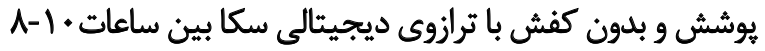

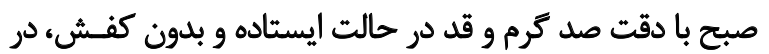

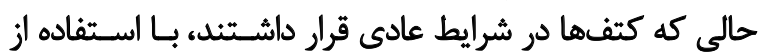

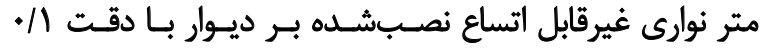

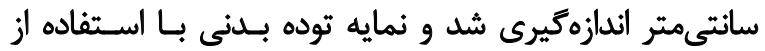

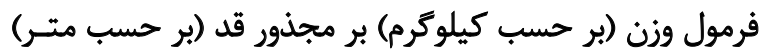

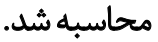

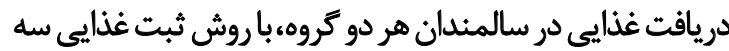

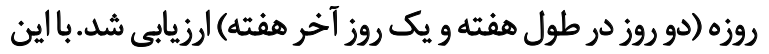

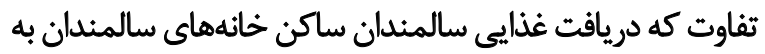

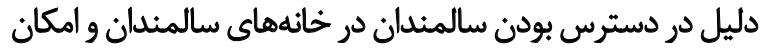

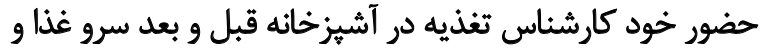

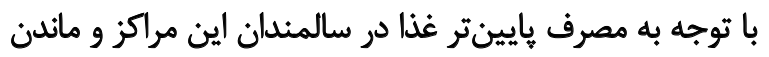

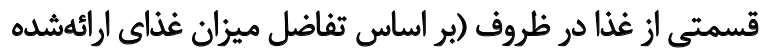

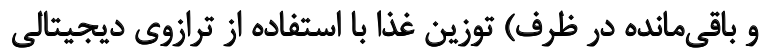

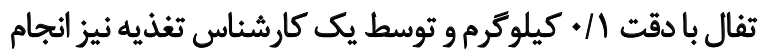

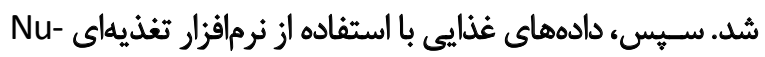

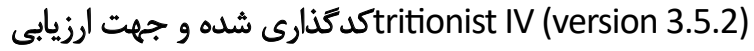

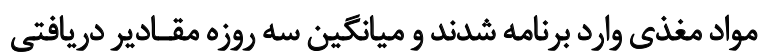

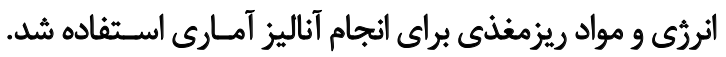

شاخص كيفيت تغذيهاى براى هر ماده مغذى مورد نظر به صورت

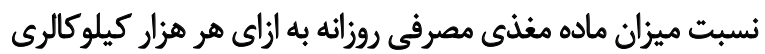

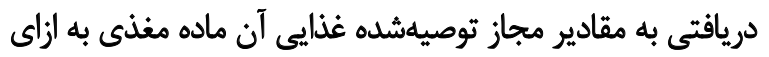

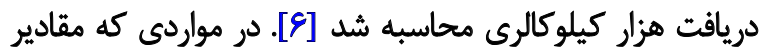

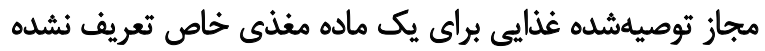

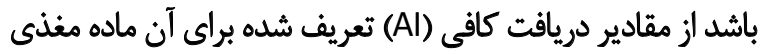

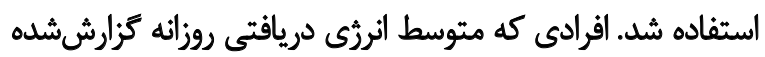

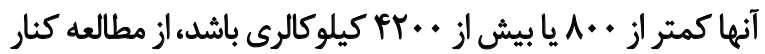

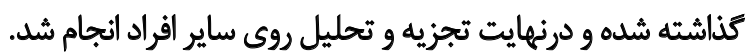

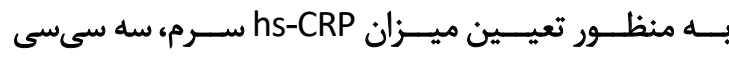

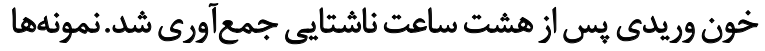

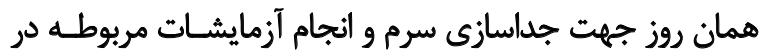

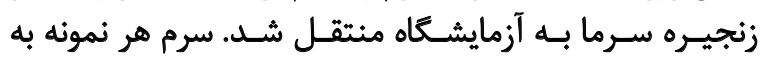

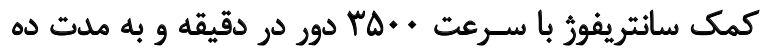

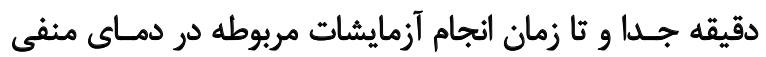

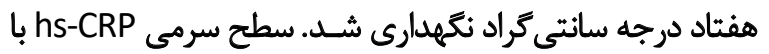

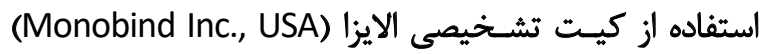

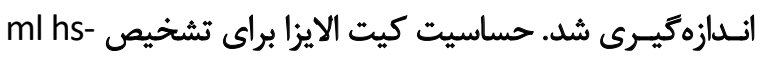
CRP/microgram 0.2 
جدول ا. اطلاعات جمعيتشناختى، تنسنجى، ميزان ائرثى و درشت مغذىهاى دريافتى در سالمندان مورد مطالعه

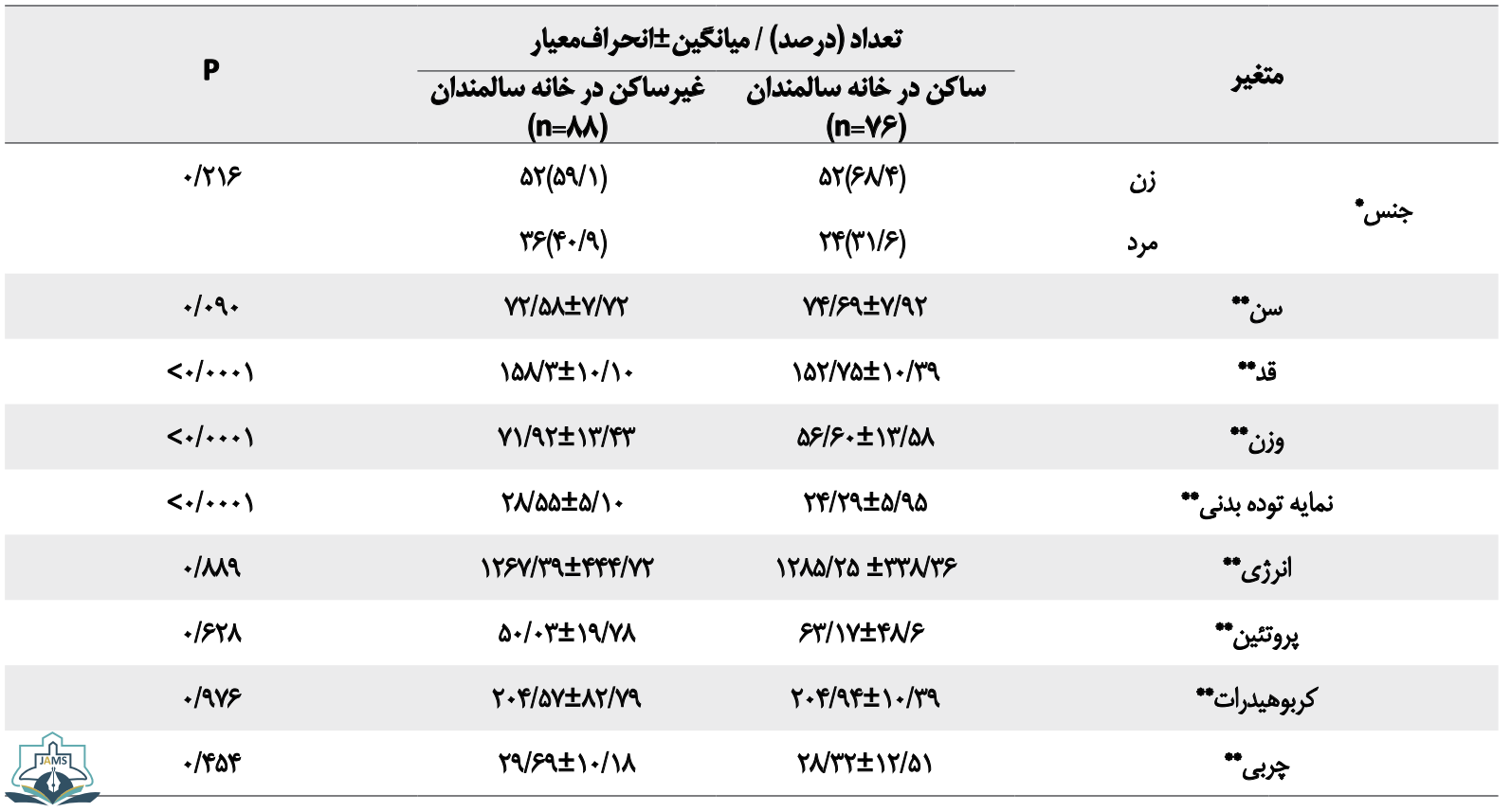

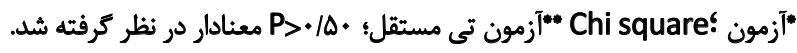

درصد) است. همجنين، در سالمندان مقيم خانههاى سالمندان

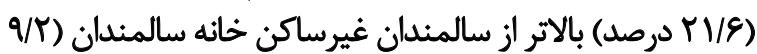

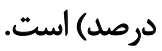

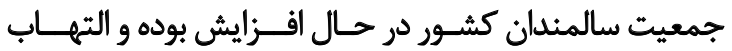

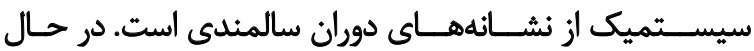

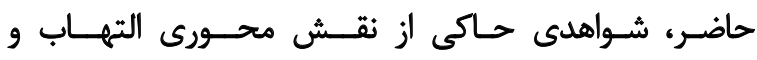

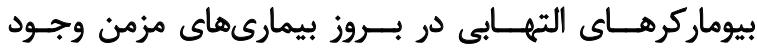

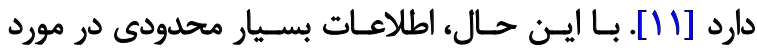

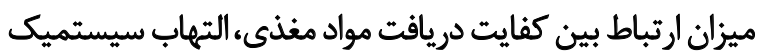
و بيوماركر هاى التهابي موجـود است.

بر اساس جستوجوى انجامكرفته، مطالعه حاضر براى براي

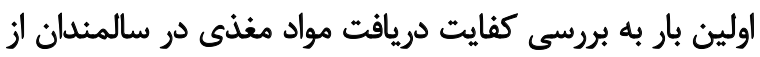

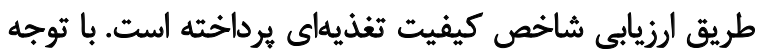

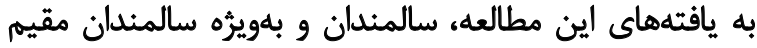

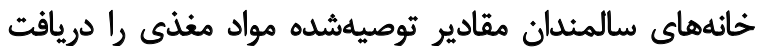

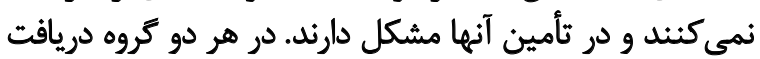

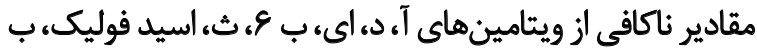

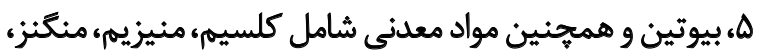

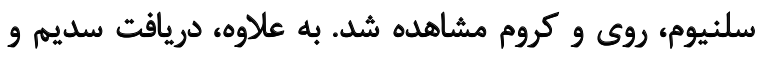

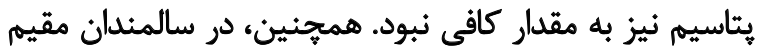

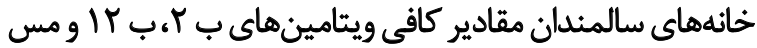

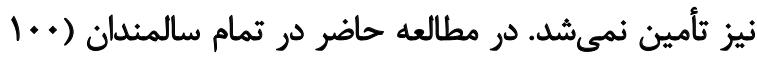

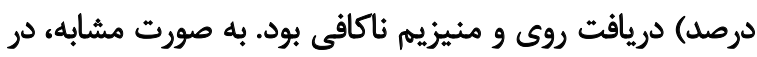

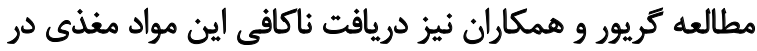

مههمترين يافتـه ايـن مطالعـه، شيوع بالاى دريافت ناكافى

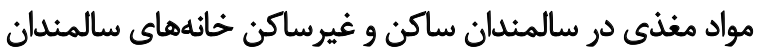

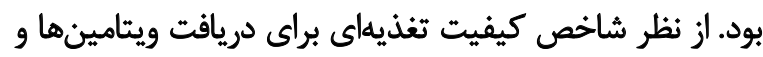

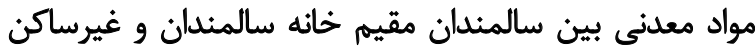

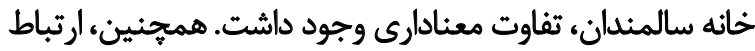

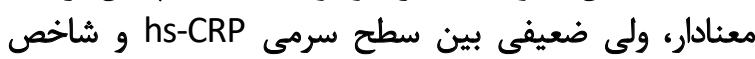

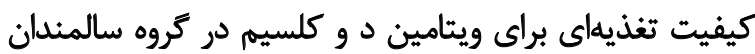

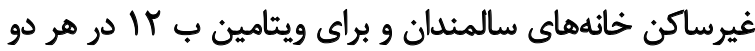

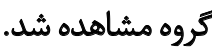

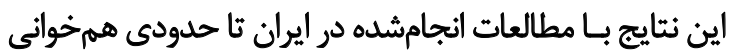

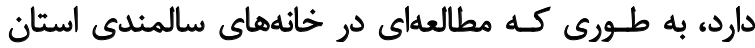

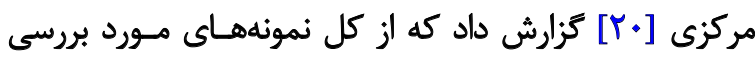

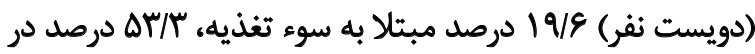
معرض خطر سوءتغذيه و تنها TV/

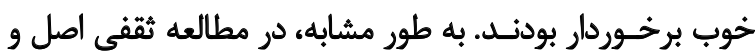

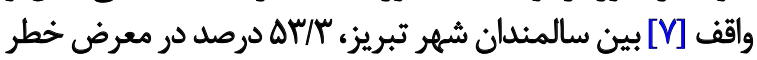

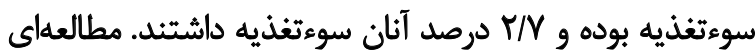

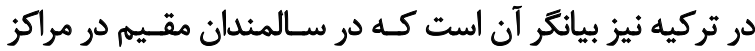

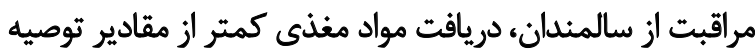

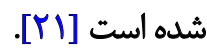
قابل ذكر است كه در هر دو كروه شاخص كيفيت تغذيهاي

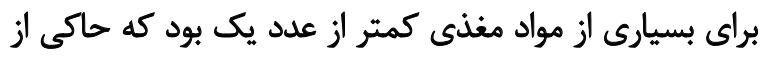

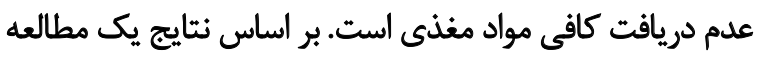
مرورى [ه] نيز شيوع سوءتغذيه در سالمندان ايراني بالا (T/T) 
جدول r. مقايسه شاخص كيفيت تغذيهاي در ماده مغذى در سالمئدان ساكن و غيرساكن در خانه سالمندان

\begin{tabular}{|c|c|c|c|}
\hline $\mathbf{P}^{*}$ & $\begin{array}{c}\text { غيرساكي دو خانه سالمندان } \\
(n=M \mid\end{array}$ & $\begin{array}{c}\text { ساكن در خانه سالمندان } \\
\text { (n=V) }\end{array}$ & ماده مغذى \\
\hline.$|1 P|$ & - $/ A r(\cdot / \Delta r-1 / \cdot 8)$ & $\cdot \operatorname{AV}(\cdot / \Delta F-T / T Y)$ & A ويتامين \\
\hline.$/ 418$ & $\cdot / \cdot+r(\cdot /+\cdots+-+1+\cdot \Delta)$ & $* 1+* r(* / *+1-+/ *+r)$ & ويتامين D \\
\hline . ITAF & $\cdot / N V(\cdot / r-\cdot / r T)$ & $\cdot / T+(* / * 9-* / T A)$ & ويتامين E \\
\hline$<+1 . \cdots+1$ & $1 / \Lambda \Delta(1 / \& A-Y / \cdot H)$ & $V / \Delta F(1 / F T-1 / A T)$ & ويتامين بـا \\
\hline$<\cdot 1 \ldots .1$ & $1 / T r(1 /+r-1 / E q)$ & $\cdot / 9 \Delta(\cdot / \Lambda \Delta-1 / \pi M)$ & ويتامين بب r \\
\hline$<+1+\ldots+1$ & $1 / \Delta N(1 / T q-1 / W)$ & $(1 / m)-1 / \Delta f) 1 / p q$ & ويثامين ب r \\
\hline.$/ \Delta r$ & $\cdot / \operatorname{Ar}(\cdot \mid A r-1 / \cdot 1)$ & $\cdot \mid A N(\cdot / \Delta A-1 / P \cdot)$ & ويثامين ب ع \\
\hline$\cdot|R T|$ &.$/ 48(\cdot / r \varepsilon-\cdot / \Delta V)$ & $\cdot / H A(\cdot / T Y-\cdot / E Y)$ & اسيد قوليك \\
\hline$<+1+\cdots+1$ & $1 / r^{m} q(\cdot / 9 r-1 / A r)$ & $.197(\cdot / \Delta 9-1 / 71)$ & ويتامين ب r|| \\
\hline$<+1+\cdots+1$ & $\cdot / \varepsilon q(\cdot / / F+-1 / 1 f)$ & $\cdot / T V(\cdot / T \Delta-\cdot / 81)$ & ويثامين ث \\
\hline$. / 9+。$ & $(I / A F-r / Y \Lambda) Y / \cdot \Lambda$ & $\left(V / \Delta T^{H}-r / A V\right) r / H r$ & آهن \\
\hline$<+1+\cdots+1$ & $\cdot / 89(\cdot / 109-. / 97)$ & $\cdot \mid g r(+/ 4 \cdot-+/ M))$ & 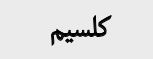 \\
\hline$<+1+\cdots+$ & $\cdot / \Delta)\left(\cdot / f|-\cdot| 8_{*}\right)$ & $\cdot / N F(+/ M I-* / F V)$ & 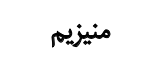 \\
\hline$<\cdot 1 \ldots .1$ &. $\mid A M(\cdot|8|-1 / M T)$ &.$/ P F(\cdot / N T-\cdot / A M)$ & 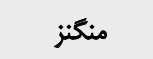 \\
\hline $.1 \cdot 1 r$ & $\cdot / M(\cdot / N F-\cdot / T a)$ & $\cdot \pi r(\cdot / N \&-\cdot / r \cdot)$ & 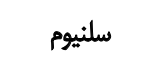 \\
\hline$<\cdot 1+\cdots \cdot \mid$ & $\cdot / V \cdot(\cdot / \Delta 8-\cdot / A V)$ &.$|8|(\cdot / \Delta \mid-. / 19)$ & ى \\
\hline $.1 .+8$ & $1 / 1 F(\cdot / 9 T-1 / 94)$ & $\cdot 198\left(\cdot / N^{\prime}-1 / \pi r\right)$ & مس \\
\hline$<+1+\cdots+1$ & $\cdot / 94\left(\cdot / M^{P}-1 / 10\right)$ & $.18 \Delta(+/ \Delta T-*|A|)$ & ويثامين ب ه \\
\hline .1958 & $\cdot \mid \Delta N\left(\cdot / N \Delta-\cdot M^{N}\right)$ & $\cdot / F \Delta(\cdot / \mu F-\cdot \mid \& \mathrm{~A})$ & بيوتين \\
\hline$+1++9$ & $\cdot / I 1(\cdot 1 \cdot 8-\cdot / M T)$ & $\cdot 1+V(+/+F-+/ N)$ & كروم \\
\hline$<+1+\infty+$ & $\cdot / A r(\cdot / \Delta V-I / / T)$ & $\cdot / \Delta \Delta(+/ K q-+/ M q)$ & سلفيم \\
\hline$<\cdot 1 \cdot \cdots \cdot \mid$ & $\cdot \operatorname{|ar}(\cdot / \mu|-| / 8 T)$ &.$/ m q(\cdot / R q-\cdot / P \Delta)$ & يثاسيم \\
\hline
\end{tabular}

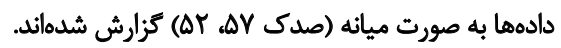
"آزمون Man Whitney U به كار رفته و ه> ه هنادار در نظر كرفته شد.

مطالعه ديكر در بين سالمئدان ايرانى [11] ميانكين و انحراف

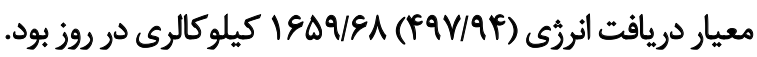

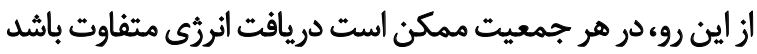

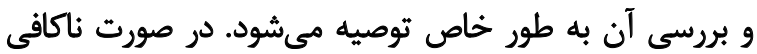

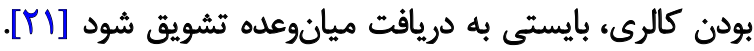

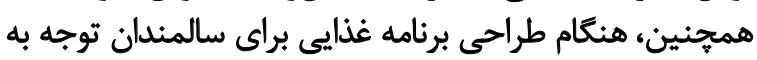

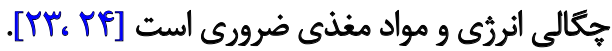

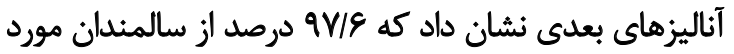

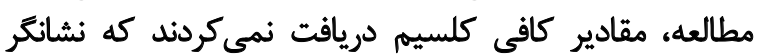

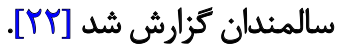

به طور كلى، با توجه به شيوع كسترده دريافت ناكافى مواد

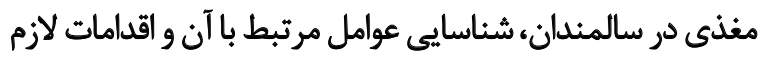

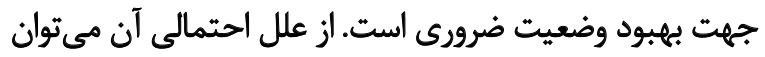

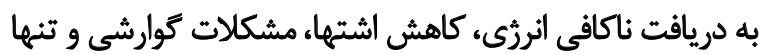

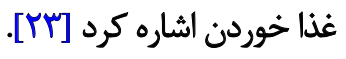
در اين مطالعه ميانكين و انحراف معيار دريافت انرزى در دران

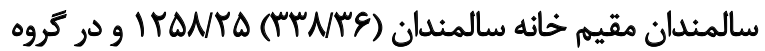
ديكر (FFF/VT) 
جدول r. توزيع فراوائى غلظت hs-CRP در سالمندان مورد مطالعه

\begin{tabular}{|c|c|c|c|c|}
\hline \multirow{2}{*}{$\mathbf{P}^{*}$} & \multicolumn{3}{|c|}{ تعداد (درصد) } & \multirow{2}{*}{ hs-CRP } \\
\hline & كل افراد & $\begin{array}{c}\text { غيرساكن در خانه سالمندان } \\
(n=M)\end{array}$ & $\begin{array}{c}\text { ساكن در خانه سالمندان } \\
\text { (n=V9) }\end{array}$ & \\
\hline \multirow[t]{3}{*}{.$/ 919$} & $\operatorname{If}(N \Delta)$ & $\Lambda(9 / 1)$ & $q(Y / q)$ & كمخطر (كمتر از (mg/L) \\
\hline & $r g(Y Y / \cdot)$ & $r \cdot(T Y / M)$ & $\mid E(Y \backslash / I)$ & با خطر متوسط (mg/L 1-3) \\
\hline & $11 f(F q / \Delta)$ & g. (FNT) & $\Delta f(M / M)$ & ميرخطر (بيشتر از mg/L3) \\
\hline
\end{tabular}

قوى است و كلسيه درون سلولى نقش بسيار مهمى در التهاب

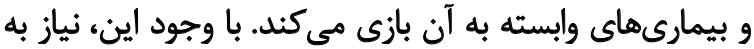

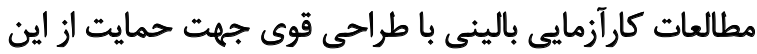

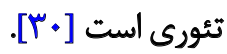

جذب و زيست دسترسى بسيارى از مواد مغذى، ازجمله

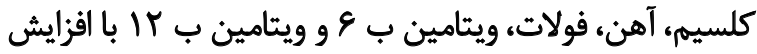

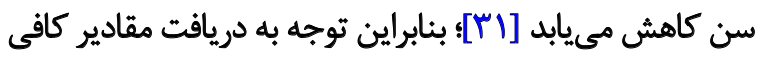

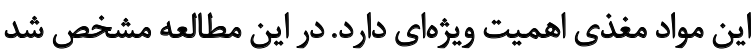

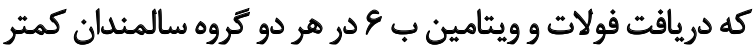

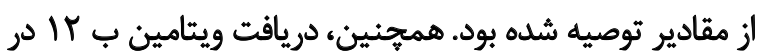
سالمئدان ساكن خانههاى سالمندان ناكافى بود.

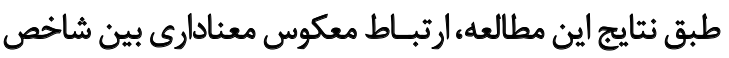

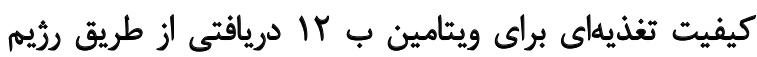

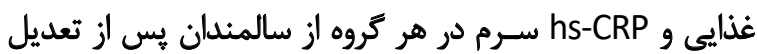

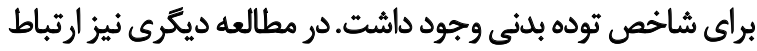

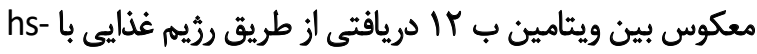

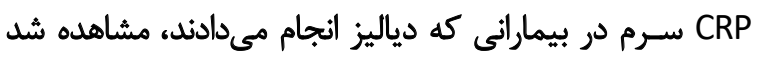

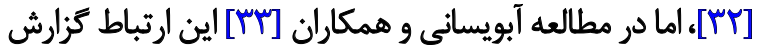

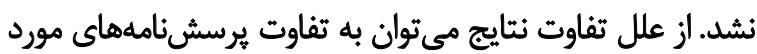

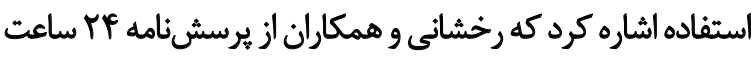

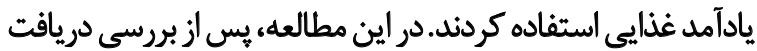
غذايى شركت كنند شاخص دقيقترى براى ارزيابى دريافت است شئ.

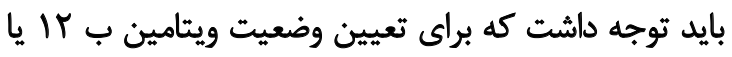

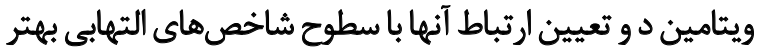

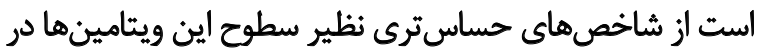

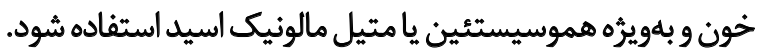

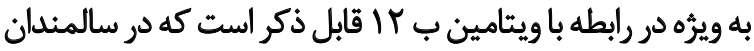

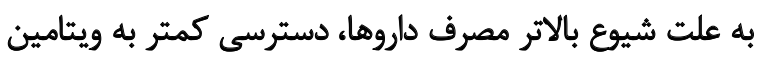

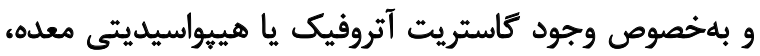

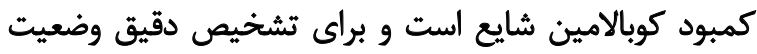

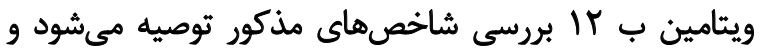

اهميت بررسى بيشتر و توجه بيشتر به تغذيه سالمندان است. در

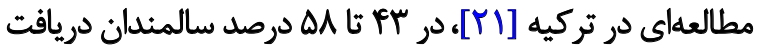

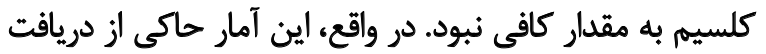

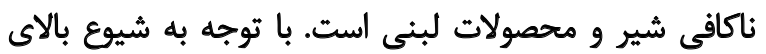

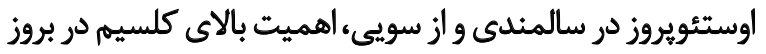

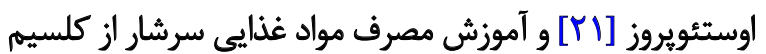
بايد در اولويت قرار كيرد.

در مطالعه حاضر، ارتبـاط معكوسى بين شاخص كيفيت

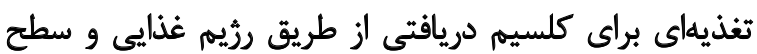

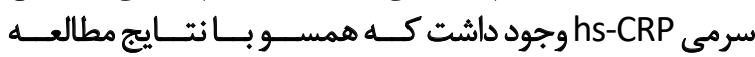

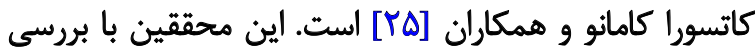

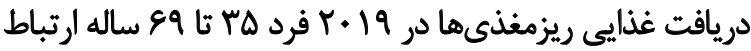

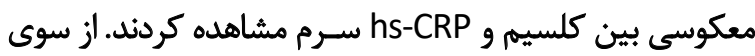

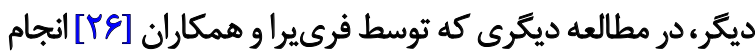

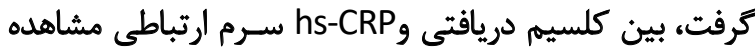

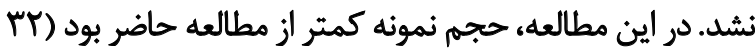

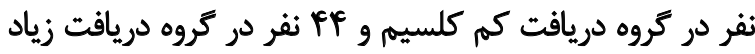

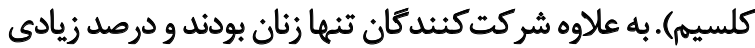

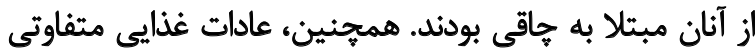

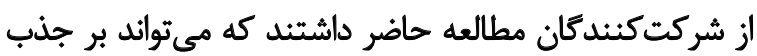

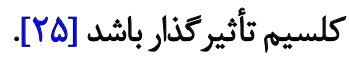

در مطالعه ديخرى كه روى مبتلايان به ديابت و هر دو جنس

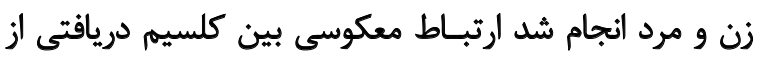

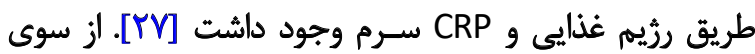

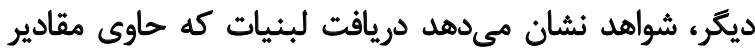

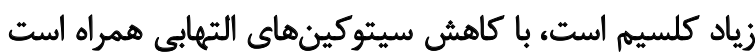

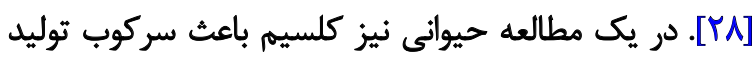

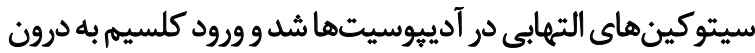

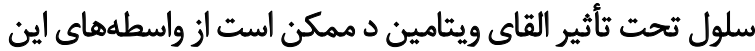
اثر باشد [T9]. بر اساس يك مطالعه مرورى در سال IV +r. آكرجه مكانيسم اصلى دخيل در ارتباط بين كلسيهم و التهاب از نظر تئورى بسيار 
جدول f. همبستّى بين شاخص INQ سراي مواد مغذى و hs-CRP درم هر كروه از سالمندان مورد مطالعه

\begin{tabular}{|c|c|c|c|c|}
\hline \multicolumn{2}{|c|}{ غيرساكن در خانه سالمندان } & \multicolumn{2}{|c|}{ ساكن در خانه سالمندان } & \multirow{2}{*}{ ماده مغذيى } \\
\hline $\mathbf{P}^{*}$ & ضريب همبستكى & $\mathbf{P}^{*}$ & ضريب همبستكى & \\
\hline $.1 \cdot 1$ &.$/ 18$ &.$/ 4 A$ & -.1 .9 & ويتامين A \\
\hline .1 .8 & $-\cdot / M Y$ & . $/ 49$ &.$- / 1 r^{m}$ & ويتامين D \\
\hline.$/ p r$ & $-\cdot 1 \cdot 1$ & .11 &.$/ r$ & ويتامين E \\
\hline$\cdot 1 N$ & -.101 &.$/ 1 f$ &.$M A$ & ويتامين ب ا \\
\hline$\cdot|A|$ & $-.10 r$ & .18 & -.1 .8 & ويتامين ب r \\
\hline.$/ 190$ & $.1+1$ & .181 & -.1 .8 & ويتامين ب ب \\
\hline .198 & $.1+4$ & .191 & $-.1 \cdot 1$ & ويتامين ب \& \\
\hline$\cdot / 1$ & $-e \cdot+r$ &.$/ A F$ & $-.1 \cdot r$ & اسيد فوليك \\
\hline 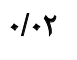 & $-\cdot / M T$ & $.1 \cdot r$ & $-\cdot / M$ & ويتامين ب r| \\
\hline .194 & .1 .0 &.$/ \mathrm{H}$ & $-+/ 11$ & ويتامين ث \\
\hline$\cdot / \Delta$ & $-+1 \cdot V$ & $\cdot M r$ & $-.1 \cdot+$ & ويتامين ب ه \\
\hline .18 & $-1 \cdot \Delta$ &.$/ 1 r$ & .119 & بيوتين \\
\hline$\cdot M$ & $-\cdot 1 \cdot r$ & 11 & $\cdot / r$ & آهن \\
\hline$\cdot 1 \cdot r A$ &.$- / 48$ &.$/ 48$ &.$- / 11$ & 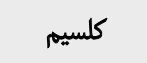 \\
\hline $.19 x^{\circ}$ & $-\cdot 1 \cdot 0$ & $\cdot r$ &.$/ 8$ & منيزيهم \\
\hline$\cdot 1 \Delta$ & -1.8 &.$/ 4 A$ & $.1 * 1$ & منكنز \\
\hline$\cdot N$ & $-+1+r$ & $\cdot / 4 \lambda$ & $.1 * 1$ & سلنيوم \\
\hline$+/ 10$ & -+110 &.$|8|$ & $+1+8$ & روى - ترى \\
\hline.$/ T V$ & .111 & $\cdot M c$ & $-* / * f$ & 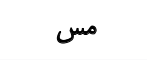 \\
\hline.$/ 19$ & .110 & .18 & -.1 .8 & كروم \\
\hline
\end{tabular}

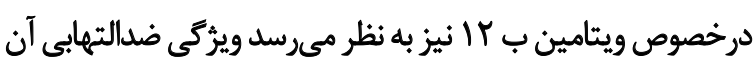

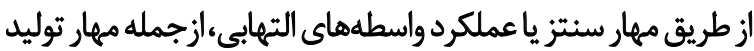

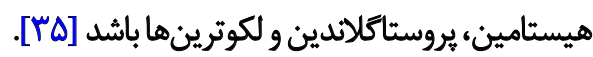

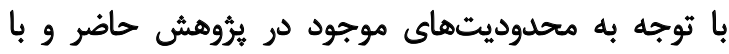

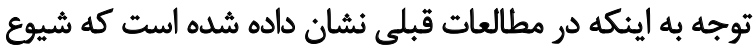

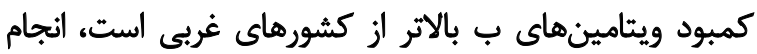

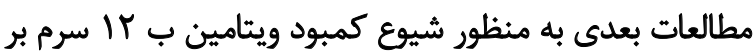

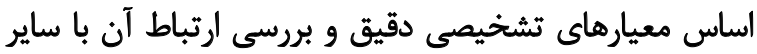
شاخصهاى التهابى توصيه مىشي تشود. يكى ديكر از محدوديتهاي اين مطالعه كه بايد در يروهشهاى

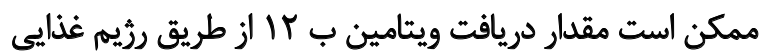

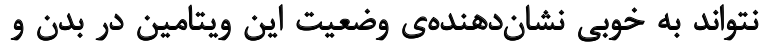

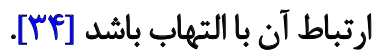
همانطور كه در متن بدان اشاره شده نوترينتهاي موجود در

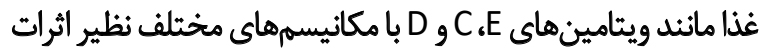

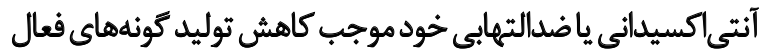

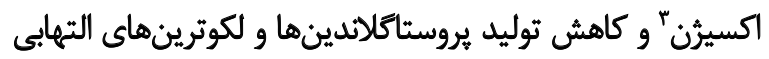

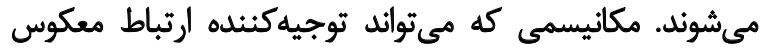

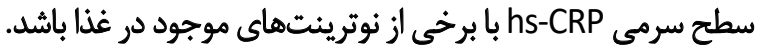


از همه سالمندان محترم، مديريت و هرسنل مراكز نكهيدارى

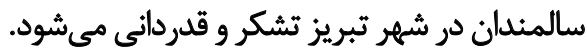

بعدى بدان توجه شود، مشكلات مالى ناشى از افزايش تعرفههاى

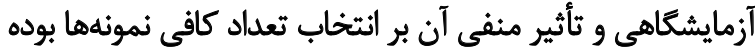

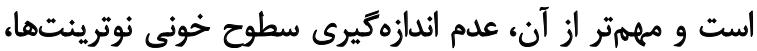

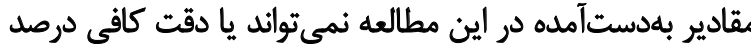

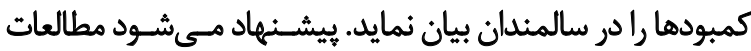

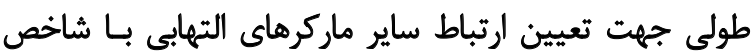

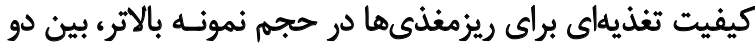

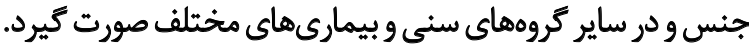

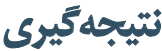

نتايج حاصـل از اين ثُروهش لزوم توجه بيشتر به وضعيت

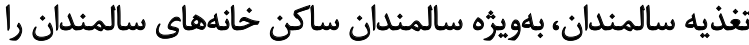

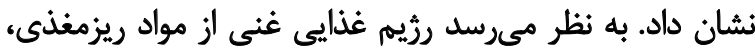

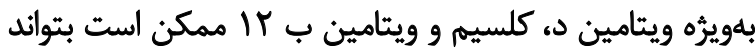

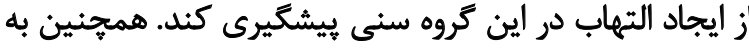

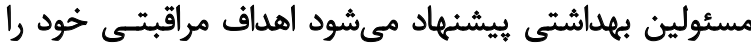

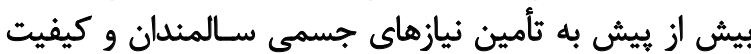

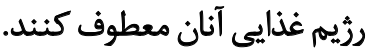

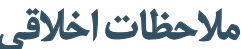

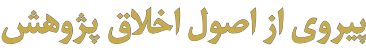

يرونش حاضر در كميته اخلاق دانشعاه علوم يزشكى تبريز با كد (TBZMED.REC.1394.152) تأييد شد.

$$
\text { ماهم مالب }
$$

ايزوهش حاضر با حمايت مالى مركز تحقيقات علوم تغذيه

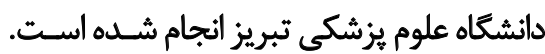

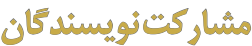

تمام نويسندكان معيارهاى استاندارد نويسندگى بر اساس

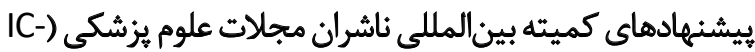
(MJE

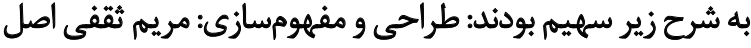

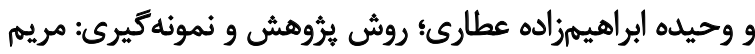

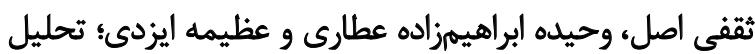

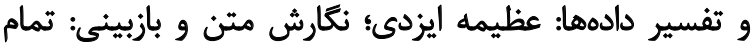

$$
\text { نويسندكان. }
$$

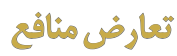

نويسندكان تصريح مىكنند كه هيجگونه تعارض منافعى درخصوص طرح حاضر وجود ندارد. 


\section{References}

[1] Leeson GW. The growth, ageing and urbanisation of our world. J Popul Aging. 2018; 11(2):107-15. [DOI:10.1007/s12062-018-9225-7]

[2] Heidari M, Shahbazi S. [Effect of self-care training program on quality of life of elders (Persian)]. Iran J Nurs. 2012; 25(75):1-8. [DOI:10.17485/ ijst/2012/v5i10.14]

[3] van Bokhorst-de van der Schueren MA, Lonterman-Monasch S, de Vries OJ, Danner SA, Kramer MH, Muller M. Prevalence and determinants for malnutrition in geriatric outpatients. Clin Nutr. 2013; 32(6):1007-11. [DOI:10.1016/j.clnu.2013.05.007] [PMID]

[4] Fávaro-Moreira NC, Krausch-Hofmann S, Matthys C, Vereecken C, Vanhauwaert E, Declercq A, et al. Risk factors for malnutrition in older adults: A systematic review of the literature based on longitudinal data. Adv Nutr. 2016; 7(3):507-22. [DOI:10.3945/an.115.011254] [PMID] [PMCID]

[5] GORJI HA, Alikhani M, Mohseni M, Moradi-Joo M, Ziaeefar H, Moosavi A. The prevalence of malnutrition in Iranian elderly: A review article. Iran J Public Health. 2017; 46(12):1603-10. [PMCID]

[6] Sorenson AW, Wyse BW, Wittwer A, Hansen RG. An Index of Nutritional Quality for a balanced diet. J Am Diet Assoc. 1976; 68(3):236-42. [DOI:10.1016/S0002-8223(21)06349-5]

[7] Saghafi-AsI M, Vaghef-Mehrabany E. Comprehensive comparison of malnutrition and its associated factors between nursing home and community dwelling elderly: A case-control study from Northwestern Iran. Clin Nutr ESPEN. 2017; 21:51-8. [DOI:10.1016/j.clnesp.2017.05.005] [PMID]

[8] Ahn Y, Lee Y, Park H, Song K. Gender and age group differences in nutrition intake and dietary quality of Korean adults eating alone: Based on Korean National Health and Nutrition Examination Survey Data, 2013-2016. Nutr Res Pract. 2021; 15(1):66-79. [DOI:10.4162/ nrp.2021.15.1.66] [PMID] [PMCID]

[9] Lee JY, Hyun YS, Kim HS. Nutritional status of Korean elderly with dementia in a long-term care facility in Hongseong. Nutr Res Pract. 2019; 13(1):32-40. [DOI:10.4162/nrp.2019.13.1.32] [PMID] [PMCID]

[10] Chung HY, Cesari M, Anton S, Marzetti E, Giovannini S, Seo AY, et al. Molecular inflammation: Underpinnings of aging and age-related diseases. Aging Res Rev. 2009; 8(1):18-30. [DOI:10.1016/j.arr.2008.07.002] [PMID] [PMCID]

[11] Sarchahi Z, Kooshki A, Rakhshani M, Tofighiyan T. [The association between macronutrients intake with high sensitivity $\mathrm{C}$-reactive protein (hs-CRP) in elderly of Sabzevar Nursing Homes (a cross-sectional study) (Persian)]. Iran J Nutr Sci Food Technol. 2017; 12(2):1-8. http://nsft. sbmu.ac.ir/article-1-2268-en.html

[12] Serino A, Salazar G. Protective role of polyphenols against vascular inflammation, aging and cardiovascular disease. Nutrients. 2019; 11(1):53. [DOI:10.3390/nu11010053] [PMID] [PMCID]

[13] Orchard T, Yildiz V, Steck SE, Hébert JR, Ma Y, Cauley JA, et al. Dietary inflammatory index, bone mineral density, and risk of fracture in postmenopausal women: Results from the women's health initiative. J Bone Miner Res. 2017; 32(5):1136-46. [DOI:10.1002/jbmr.3070] [PMID] [PMCID]

[14] Kroushavi M, Behrooz M, Rashidkhani B, Bahadori N, Hekmatdoost A. [Association between index of nutritional quality and multiple sclerosis (Persian)]. J Sch Public Health Inst Public Health Res. 2015; 12(3):53-67. http://sjsph.tums.ac.ir/article-1-5192-en.html

[15] Vahid F, Hatami M, Sadeghi M, Ameri F, Faghfoori Z, Davoodi SH. The association between the Index of Nutritional Quality (INQ) and breast cancer and the evaluation of nutrient intake of breast cancer patients: A case-control study. Nutrition. 2018; 45:11-6. [DOI:10.1016/j. nut.2017.06.011] [PMID]

[16] Vahid F, Hekmatdoost A, Mirmajidi S, Doaei S, Rahmani D, Faghfoori Z. Association between index of nutritional quality and nonalcoholic fatty liver disease: The role of vitamin D and B group. Am J Med Sci. 2019; 358(3):212-8. [DOI:10.1016/j.amjms.2019.06.008] [PMID]

[17] Vahid F, Rashvand S, Sadeghi M, Hekmatdoost A. The association between index of nutritional quality and ulcerative colitis: A case-control study. J Res Med Sci. 2018; 23:67. [DOI:10.4103/jrms.JRMS_555_17] [PMID] [PMCID]

[18] 18. Park HS, Park JY, Yu R. Relationship of obesity and visceral adiposity with serum concentrations of CRP, TNF- $\alpha$ and IL-6. Diabetes Res Clin Pract. 2005; 69(1):29-35. [DOI:10.1016/j.diabres.2004.11.007] [PMID]

[19] Kord VH, Rahmani J, Fatahi S, Tajik S, SHAB BS. [Relationship between alternative healthy eating index (AHEI-2010) with obesity status, serum level of 25-Hydroxyvitamin D, hs-CRP in the Elderly of Tehran City, (Iran) (Persian)]. Qom Univ Ned Sci. 2018; 12(5):53-61. [DOI:10.29252/ qums.12.5.53]

[20] Ebrahimi Fakhar MR, Zand S. [Nutritional status and associated factors in elderly residents in nursing homes (Persian)]. J Payesh. 2013 12(2):143-9. http://payeshjournal.ir/article-1-375-en.html

[21] Rakıcıoğlu N, Aksoy B, Tamer F, Yıldız EA, Samur G, Pekcan G, et al. Nutritional status and eating habits of the institutionalised elderly in Turkey: A follow-up study. J Hum Nutr Diet. 2016; 29(2):185-95. [DOI:10.1111/jhn.12320] [PMID]

[22] Gerrior SA. The nutrient and anthropometric status of physically active and inactive older adults. J Nutr Educ Behav. 2002; 34(S1):S5-13. [DOI:10.1016/S1499-4046(06)60305-9]

[23] Shahar D, Shai I, Vardi H, Fraser D. Dietary intake and eating patterns of elderly people in Israel: Who is at nutritional risk? Euro J Clin Nutr. 2003; 57(1):18-25. [DOI:10.1038/sj.ejcn.1601523] [PMID]

[24] Lammes E, Törner A, Akner G. Nutrient density and variation in nutrient intake with changing energy intake in multimorbid nursing home residents. J Hum Nutr Diet. 2009; 22(3):210-8. [DOI:10.1111/j.1365277X.2008.00925.x] [PMID]

[25] Katsuura-Kamano S, Uemura H, Yamaguchi M, Nakamoto M, Bahari $\mathrm{T}$, Miki K, et al. Dietary calcium intake is associated with serum highsensitivity C-reactive protein level in the general Japanese population. J Clin Biochem Nutr. 2018; 62(1):89-93. [DOI:10.3164/jcbn.17-48] [PMID] [PMCID]

[26] Da Silva Ferreira T, Torres MRSG, Sanjuliani AF. Dietary calcium intake is associated with adiposity, metabolic profile, inflammatory state and blood pressure, but not with erythrocyte intracellular calcium and endothelial function in healthy pre-menopausal women. Brit J Nutr. 2013 110(6):1079-88. [DOI:10.1017/S0007114513000111] [PMID]

[27] Chung HY. [Dietary Calcium intake is associated with blood lipid profile, blood pressure, inflammatory state and Insulin resistance in type 2 diabetes patients (Korean)]. Korean J Food Nutr. 2016; 29(2):290-9. [DOI:10.9799/ksfan.2016.29.2.290]

[28] Stancliffe RA, Thorpe T, Zemel MB. Dairy attentuates oxidative and inflammatory stress in metabolic syndrome. Am J Clin Nutr. 2011; 94(2):422-30. [DOI:10.3945/ajcn.111.013342] [PMID] [PMCID]

[29] Sun X, Zemel MB. Calcium and 1, 25-dihydroxyvitamin D3 regulation of adipokine expression. Obesity. 2007; 15(2):340-8. [DOI:10.1038/ oby.2007.540] [PMID] 
[30] Soares MJ, Pannu PK, Calton EK, Reid CM, Hills AP. Vitamin D status and calcium intake in systemic inflammation, Insulin resistance and the metabolic syndrome: An update on current evidence. Trends Food Sci Technol. 2017; 62:79-90. [DOI:10.1016/j.tifs.2017.01.009]

[31] De Groot C, West C, Van Staveren W. Meeting nutrient and energy requirements in old age. Maturitas. 2001; 38(1):75-81. [DOI:10.1016/ S0378-5122(00)00193-6]

[32] Martín-del-Campo F, Batis-Ruvalcaba C, González-Espinoza L, RojasCampos E, Ángel JR, Ruiz N, et al. Dietary micronutrient intake in peritoneal dialysis patients: Relationship with nutrition and inflammation status. Perit Dial Int. 2012; 32(2):183-91. [DOI:10.3747/pdi.2010.00245] [PMID] [PMCID]

[33] Abavisani M, Sarchahi Z, Kooshi A, Tofighiyan T, Rakhshani MH. The relationship of micronutrients intake and anthropometric indexes with high-sensitivity C-Reactive protein (hs-CRP) in the elderly living in nursing home, Sabzevar, Iran. Prof RK Sharma. 2018; 12(4):4133. [DOI:10.5958/0973-9130.2018.00211.6]

[34] Vakili MA, Forooghan M, Nojomi M, Ghaleh Bandi MF, Khodabandeloo $\mathrm{N}$. [A survey on serum levels of B12, folate, and homocyctein in healthy elderly Tehranis (Persian)]. Razi J Med Sci. 2009; 16(63):189-200. http:// rjms.iums.ac.ir/article-1-1260-en.html

[35] Hosseinzadeh H, Moallem SA, Moshiri M, Sarnavazi MS, Etemad L. Anti-nociceptive and anti-inflammatory effects of cyanocobalamin (vitamin B12) against acute and chronic pain and inflammation in mice. Arzneimittelforschung. 2012; 62(7):324-9. [DOI:10.1055/s-0032-1311635] [PMID] 
This Page Intentionally Left Blank 